\title{
SIMULTANEOUS BIOMASS FLAME TEMPERATURE AND SPECTRAL EMISSIVITY ESTIMATION BY INVERSE METHOD
}

\section{CARLOS T. SALINAS ${ }^{1 *}$, LEONARDO GONZALES ${ }^{2}$, PAULO ROBERTO T. CÂNDIDO $^{3}$ AND DANIEL MARCELO-ALDANA ${ }^{4}$}

\author{
${ }^{1}$ Santa Cecilia University/Universidad de Piura \\ Rua Cesário Mota 08, Sala F-34, Santos (SP) CEP 11.045-040, Brazil/Av. Ramón Mugica 131, Urb. \\ San Eduardo, Piura, Perú \\ csalinas_99@yahoo.com, carlossalinas@unisanta.br \\ ${ }^{2}$ Universidad de Piura \\ Av. Ramón Mugica 131, Urb. San Eduardo, Piura, Perú \\ lgonzalesan@gmail.com \\ ${ }^{3}$ Santa Cecilia University \\ Rua Cesário Mota 08, Sala F-34, Santos (SP) CEP 11.045-040, Brazil, \\ paulocandido@sabesp.com.br \\ ${ }^{4}$ Universidad de Piura \\ Av. Ramón Mugica 131, Urb. San Eduardo, Piura, Perú \\ daniel.marcelo@udep.edu.pe
}

Key words: Flame temperature, Biomass, Spectral analysis, Two-color method, Flame emissivity.

\begin{abstract}
This work presents a numerical and experimental study in a laboratorial rig to measure local flame temperature during the biomass combustion. Most of practical situations of biomass combustion is a transient and non-stable phenomenon. A spectral analysis method in the visible spectrum range was used for measurement of local temperatures in a sugarcane bagasse flame. The two-color method considering spectral flame emissivity variation joint with an inverse numerical procedure is used to simultaneous estimation of flame temperature and spectral emissivity. Also, a sequential iterative numerical procedure is tested. It includes the application of two-color method considering grey emissivity between two near spectral intensity data in a first step. In a second step and iterative procedure considering spectral emissivity variation along whole spectral range is applied. To apply the numerical methods was used several spectral intervals in the visible range. In inverse estimation, the LevenbergMarquardt method is used and a polynomial and a cosine models for estimation of coefficients were tested. Six test of biomass combustion were made focusing the sensor to the reaction zone, and spectral data collected. The flame temperature estimated for the six spectral data were closed to 1530 to $1540 \mathrm{~K}$. Also, the spectral emissivity is closed in all sixcombustion test. Instantaneous bagasse flame temperature in the range of $1400 \mathrm{~K}$ to $1500 \mathrm{~K}$ in the reactive combustion zone were found. An image processing method was used to measure the temperature in the same reactive combustion zone and the comparison show
\end{abstract}


reasonable agreement. The results in this work also are in reasonable agreement with results in literature.

\section{INTRODUCTION}

Combustion temperature and environmental pollutant emissions are some of the most important parameters to know when attempting to diagnose a combustion system. The quality of the process is directly related to the temperature of the combustion flame. Therefore, it is necessary to use an accurate method to measure this temperature. Over the years, different methods have been developed to measure the temperature of a flame within a combustion chamber. A large part of these methods is based on the two-color method for calculating temperature, which uses as input the spectral intensity found at two different wavelengths. In its most basic approach, this method considers that the spectral emissivity remains constant throughout the two wavelengths chosen to calculate the temperature. However, this condition is not always met. An experimental system that uses an empirical model of spectral calculation and that can measure the wall temperature and the temperature of the flame inside an oven, using information from the radiation collected in the visible spectrum is present in [1]. A spectral analysis that allows determining if the grey body condition is fulfilled for certain types of flame is proposed in [2]. For the solidified gasoline and coal flame the grey body condition was fulfilled, however, for the red phosphorus flame the emissivity could not be considered independent of the wavelength.

Various works have wavelength are proposer

that seeks to estimate

way that the error is $t$

(dependent on the wave
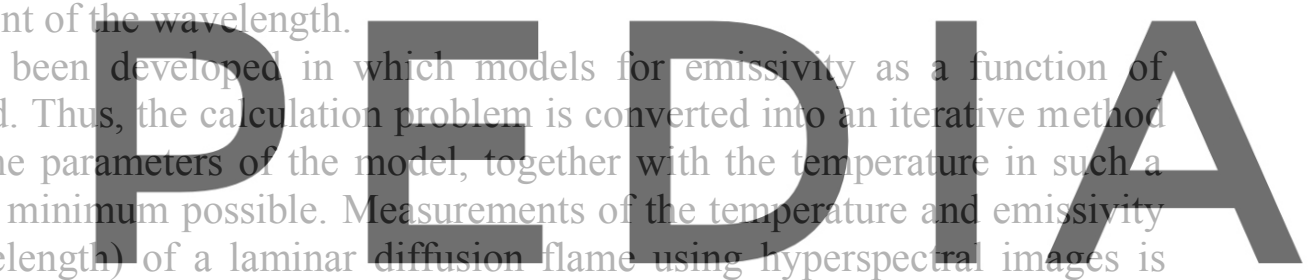

carried out in [3]. And in [4] is present the measurement of the temperature distribution and

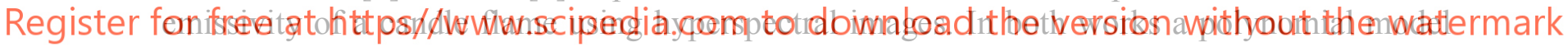
was used to represent emissivity as a function of wavelength. In [5] is present a study of an improved two-color method, which integrates a model of the emissivity ratio using a sinusoidal model and its application in air-fuel flames of industrial furnaces. Inverse methods [6] is used in different applications in thermal sciences and can be applied in simultaneous estimation of flame temperature and emissivity.

This work presents a numerical and experimental study in a laboratorial rig to measure local flame temperature during the biomass combustion using a spectrometric method, the two-color method and the Levenberg-Marquardt inverse method to estimate simultaneously the local flame temperature and emissivity.

\section{MATERIALS AND EXPERIMENTAL SET-UP}

\subsection{Experimental rig}

An experimental test ring is mounted in the laboratory to obtain the spectrum of the bagasse flame during a bagasse combustion process to calculate the flame temperature. A 
combustion chamber was used together with a spectrometric system. Combustion chamber is a small vertical tubular combustion chamber type as is show in figure 1(a), to simulate grate bagasse combustion type. The furnace has many viewing ports in the tube wall to install the sensor of the spectrometric system in different level positions. A small chimney is installed in the upper wall of the furnace as an exit for combustion gases allowing the circulation of fresh air into the furnace supporting the combustion process. The combustion process is carried out in a batch procedure using small samples of sugarcane bagasse between $2 \mathrm{~g}$ to $5 \mathrm{~g}$.

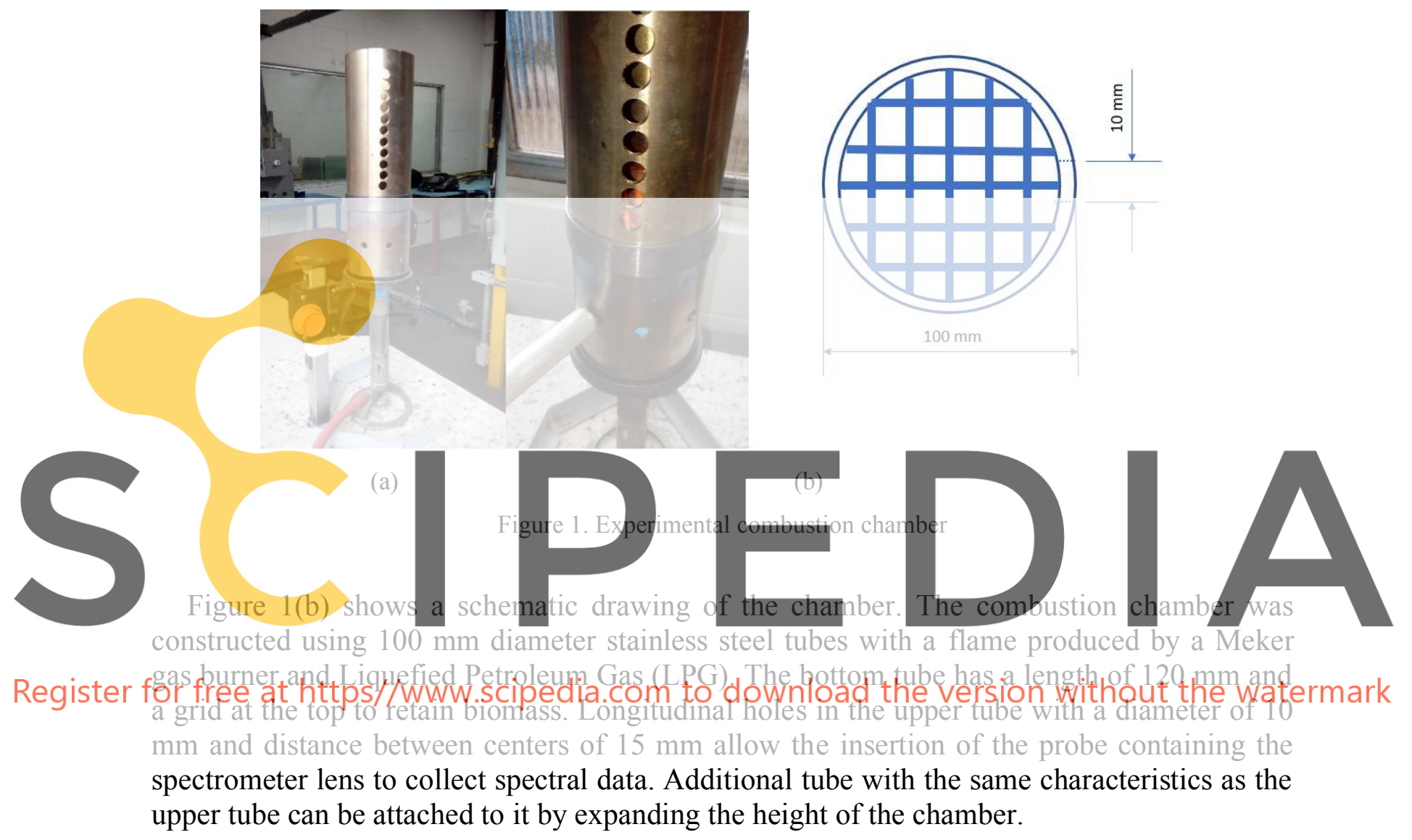

\subsection{Bagasse characteristics}

The bagasse samples for the combustion test in the laboratory were collected at a power plant in Pirassununga City, Sao Paulo State. The bagasse samples were collected in the same condition as they are used to burn at the boiler with $50 \%$ of moisture. During the transporting of the samples some variation of moisture occurred. Before the experimental tests in the laboratory, measurement of the sample moisture was carried to the chemical department laboratory at Santa Cecilia University only after following the procedure stated in [7]. Three bagasse samples of approximately $1 \mathrm{~g}$ are used for measuring the moisture content and the result is show in table 1. Routine reports in the power plant includes information of the proximate analysis of bagasse burned in the boiler furnace. The ultimate analysis in dry and ash free basis of bagasse in the power plant is presented in Table 2. 
Table 1. Average Moisture of Bagasse Samples in Laboratorial Tests

\begin{tabular}{|c|c|c|c|c|}
\hline Test & Moist Sample (g) & Dry Sample (g) & Moisture (\%) & Average Moisture (\%) \\
\hline 1 & 1.0386 & 0.7269 & 30.0115 & 27.9748 \\
\hline 2 & 0.9914 & 0.7059 & 26.9013 & \\
\hline 3 & 0.9929 & 0.7247 & 27.0117 & \\
\hline
\end{tabular}

Table 2. Ultimate Analysis of Some Samples in routine report in the power plant.

\begin{tabular}{|l|l|l|l|l|l|l|}
\hline $\mathrm{C} \%$ & $\mathrm{H} \%$ & $0 \%$ & $\mathrm{~N} \%$ & Sulfur \% & Chlorine \% & $\begin{array}{l}\text { High heating } \\
\text { Value MJ/Kg }\end{array}$ \\
\hline 48.17 & 6.55 & 44.9 & 3.64 & Less to 0.10 & 0.0449 & 16.12 \\
\hline
\end{tabular}

\subsection{Spectrometric system and Imaging system}

The spectrometer system consists of a spectrometer, a measuring probe and a portable computer. An AvaSpec-USB2048 Fiber-Optic Spectrometers with 2048 pixels is used to process the incoming light data. The measurement wavelength range of the spectrometer was $200 \mathrm{~nm}$ to $1100 \mathrm{~nm}$.

probe consists of a do lens, screws onto the beam of radiation into through a USB cable paper, the exposure (integration) time is about

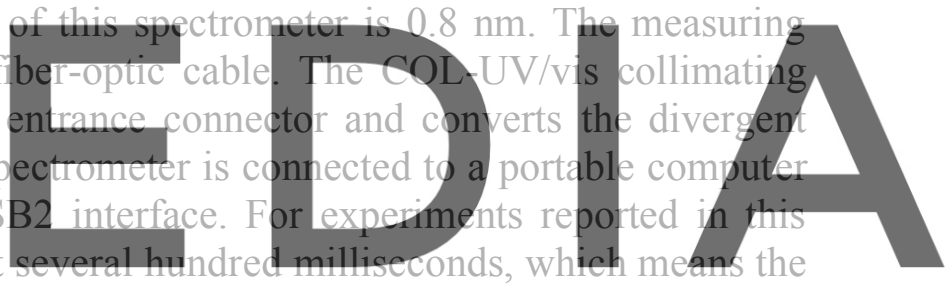
measurement of radiative intensifies at different wavelengths by the spectrometer is

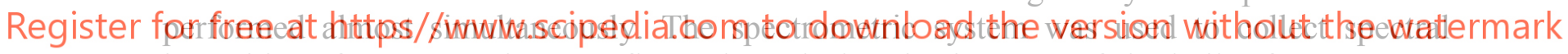
intensities of sugarcane bagasse flame through the viewing port of the boiler furnace every one second. Figure 2 shows a scheme of the spectrometric system.

The imaging system consists of a color CCD camera, an objective lens with a viewing angle field of $90^{\circ}$ in the horizontal direction fixed at the top end of the CCD camera and a laptop with a frame grabber. The flame radiation conveyed by the lens entered the color CCD camera. The shutter speed of the color camera is adjustable from 1/120 to $1 / 10000 \mathrm{~s}$. The video signal from the CCD camera is transferred into the laptop through a video cable. A USB frame-grabber transfers the CCD camera's analogue signal into a two-dimensional digital color image with 24-bit true color. Combined with a DELL Latitude D630 laptop, the system provides a frame rate of 24 frames / s with a 24-bit true color. Every color flame image is saved as a 24-bit RGB Windows Bitmap (BMP) file. When the CCD camera is installed in the boiler furnace to capture flame images on-line, it should be cooled by air or water. However, while the portable system works, flame capturing time in every viewing port is very short. Furthermore, the objective lens and CCD camera were packaged by a steel shell. As a result, there is no cooling air for the measurement in the power plant. 

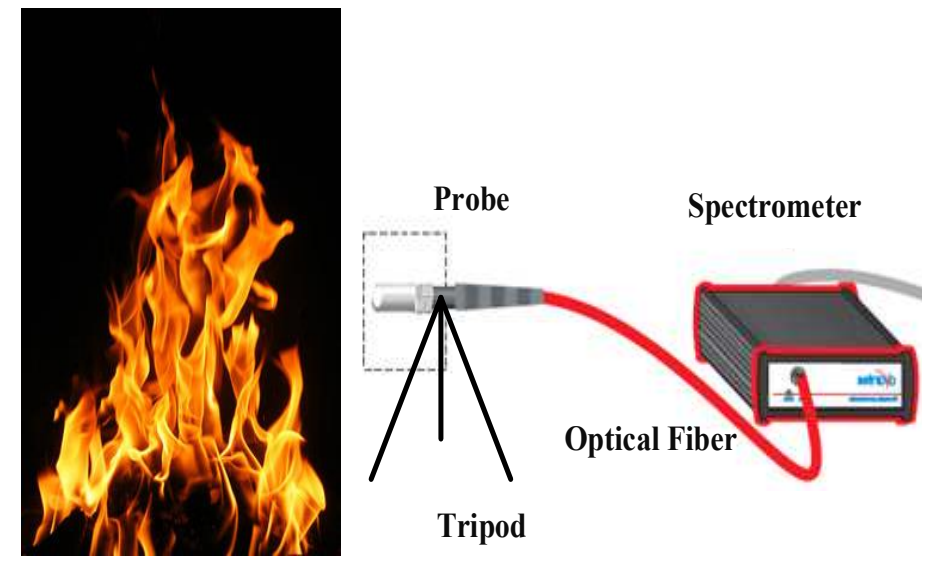

Furnace

Tripod

Figure 2. Scheme of the spectrometric system

The combustion chamber has two tubes. The bottom tube has a length of $120 \mathrm{~mm}$ and a grate at the top to simulate combustion of biomass in grate. Longitudinal holes in the upper tube with a diameter of $10 \mathrm{~mm}$ and distance between centers of $15 \mathrm{~mm}$ allow the insertion of the spectrometer lens to collect spectral data and select position to focus the reaction zone.

Six tests of bagasse combustion were made in the tubular combustion chamber simulating grate combustion. Bagasse samples of $3 \mathrm{~g}$ wer the diffusion type, and spectral the integration adjusted by the spectron that, it is select a spectra data with emissions near of 60000 counts.
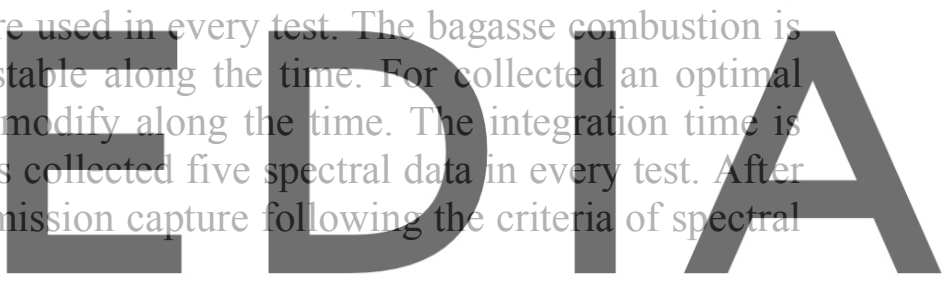

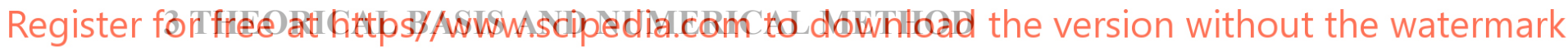

\subsection{Theoretical basis}

Every body with a temperature above absolute zero emits thermal radiation. Thermal radiation energy is transmitted by electromagnetic waves at different wavelengths (or frequencies) and, therefore, does not depend on physical contact between bodies to occur. The rate of energy emitted by radiation by a body ( $\mathrm{E}$ - emissive power) is related to its temperature by the equation (1) [8].

$$
E=\varepsilon \sigma T^{4}
$$

where $\varepsilon$ is the emissivity of the body that depends on its physical characteristics; $\sigma$ is the Stefan-Boltzmann constant and $\mathrm{T}$ the body temperature in $\mathrm{K}$ [8]. It is therefore possible to estimate the temperature of a body by measuring the radiation emitted by it, even from a distance, as long as we know the emissivity of the body and can treat the radiation reflected by it from other sources.

Spectrometers are used to measure the emissive power, collecting the electromagnetic waves coming from the body. They provide the emissive power per wavelength of the 
electromagnetic spectrum, called the spectral emissive power. Electromagnetic waves are of various lengths (or frequencies), the electromagnetic spectrum encompasses all of these wavelengths. For example, the range of visible light corresponds to the wavelength range from 400 to $760 \mathrm{~nm}$. Planck's law for black bodies, idealized bodies that, for any temperature, emit maximum of radiation at each wavelength of the spectrum in a diffuse way (regardless of direction) and that absorb all incident radiation, can be adapted with inclusion of emissivity $(\varepsilon)$ to relate the spectral emissive power to the temperature of real bodies as (2) [8].

$$
E(\lambda, T)=\varepsilon \frac{2 \pi h c^{2}}{\lambda^{5}\left(e^{\frac{C_{2}}{\lambda T}}-1\right)} \quad\left(W / m^{2} n m\right)
$$

where $\lambda$ is the wavelength for which the spectral emissive power is being determined $(E), \mathrm{T}$ is the body temperature, h Planck's constant, $c$ is the speed of light and $C_{2}$ is $h c / k$ where $k$ is the Boltzmann constant [8].

\subsection{Formulation two-color method}

For wavelengths between $400 \mathrm{~nm}$ to $1000 \mathrm{~nm}$ and temperatures between $800 \mathrm{~K}$ to $2200 \mathrm{~K}$, conditions in which the experiments in this work were carried out, the term $e^{\frac{C_{2}}{\lambda T}}$ in (2) is much higher than 1, making it possible to simplify (2) to (3), which corresponds to the equation of Wien's radiation law [9].
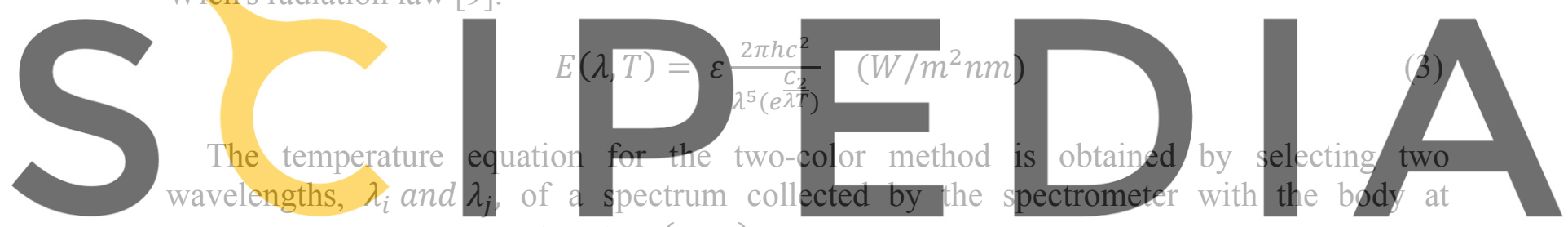

temperature $\mathrm{T}$. Dividing $E\left(\lambda_{i}, T\right) / E\left(\lambda_{j}, T\right)$ on both sides of (3) and isolating the $\mathrm{T}$ we get the

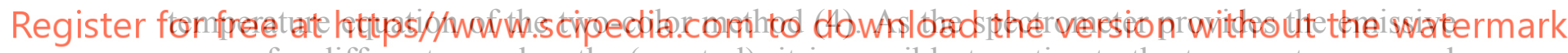
power for different wavelengths (spectral), it is possible to estimate the temperature several times by varying the wavelength pairs [9],

$$
T=\frac{C_{2}\left(1 / \lambda_{j}^{-1 / \lambda_{i}}\right)}{\left(\operatorname{Ln}\left(E\left(\lambda_{i}, T\right) / E\left(\lambda_{j}, T\right)\right)+\operatorname{Ln}\left(\varepsilon^{\varepsilon_{j}} / \varepsilon_{i}\right)+5 \operatorname{Ln}\left(\lambda_{i} / \lambda_{j}\right)\right)}
$$

where $T$ is the estimated temperature; $C_{2}$ is $h c /{ }_{k}$ (h Plank's constant; $\mathrm{k}$ is the Boltzmann constant; $c$ the speed of light), corresponding to $1,43878 \times 10^{-2} m K . \lambda_{i}$ and $\lambda_{j}$ are the wavelengths. $E\left(\lambda_{i}, T\right)$ and $E\left(\lambda_{j}, T\right)$ the spectral emissive powers at the wavelengths $\lambda_{i}$ and $\lambda_{j}$ in $\left(W \cdot m^{-2} \cdot n m^{-1}\right) . \varepsilon_{i}$ and $\varepsilon_{j}$ are emissivities at wavelengths $\lambda_{i}$ and $\lambda_{j}$.

Soot particles in the flame have a gray body property, a body in which the rate of change in emissivity as a function of variation in wavelengths approaches zero. For nearby $\lambda_{i} e \lambda_{j}$ (less then $128 \mathrm{~nm}$ ), one can simplify (4) assuming that $\varepsilon_{i} / \varepsilon_{j} \cong 1$, which allows us to estimate temperatures using (5) [10]. In step 1 of the work, we used the $30 \mathrm{~nm}$ distance between wavelengths and (5). 


$$
T_{i, j}=\frac{C_{2}\left(1 / \lambda_{j}{ }^{-1} / \lambda_{i}\right)}{\left(\operatorname{Ln}\left(I_{i} / I_{j}\right)+5 \operatorname{Ln}\left(\lambda_{i} / \lambda_{j}\right)\right)}
$$

\subsection{Numerical procedure}

Temperatures are calculated using the two-color method for wavelength pairs $\lambda$ and $\lambda+\Delta \lambda$, with $\Delta \lambda$ equal to $30 \mathrm{~nm}$. The temperatures were estimated for the entire range of wavelengths provided by the spectrometer, outliers were removed statistically using the Chauvenet Criterion. The Levenberg-Marquardt Inverse Method [6] was used to calculate simultaneously the spectral emissivity variation and the flame temperature. In the inverse method were used the procedure of parameters estimation and polynomial and sinusoidal models.

\section{RESULTS AND DISCUSSION}

Six spectral data of flame emission were collected in six bagasse combustion experiments.

Figure 3(a) shows the temperatures calculated using the equation (5) for three collected spectra using the two-color method for wavelength pairs $\lambda$ and $\lambda+\Delta \lambda$, with $\Delta \lambda$ equal to $30 \mathrm{~nm}$. The choice of $\Delta \lambda=30 \mathrm{~nm}$ due to the greater strability of the estimated temperatures compared to lower values of $\Delta \lambda$. Temperatures were estimated for the entire wavelengths provided by the spectrometer, then, for experiment 1 is show in figure $3(\mathrm{~b})$. demarked by red square, the emissivity is approx the temperature. In sequence the flame temper.
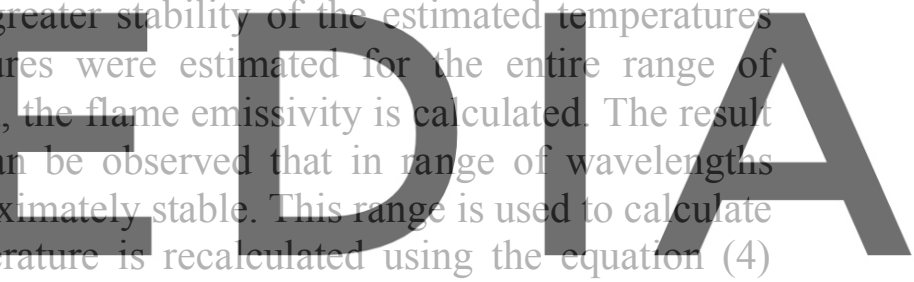
considering the flame emissivity. After few iterations, the result converges. The flame

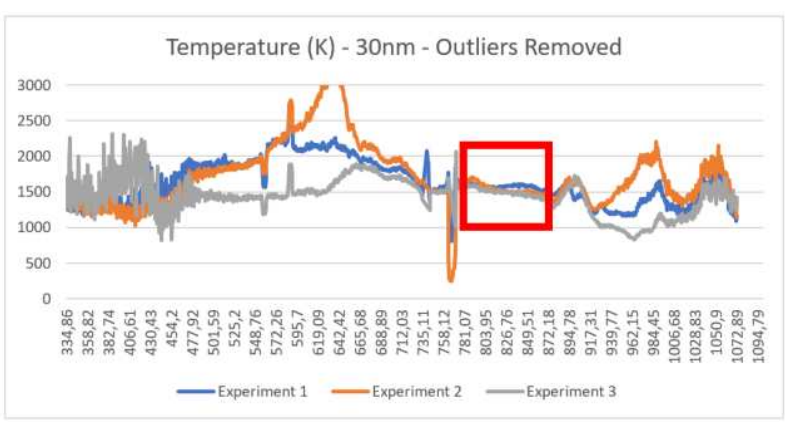

(a)

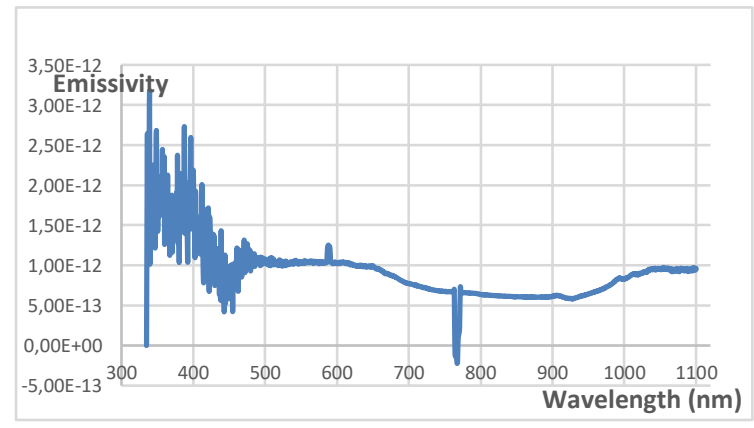

(b)

Figure 3. Estimated flame temperature and emissivity using $\Delta \lambda$ of $30 \mathrm{~nm}$ 


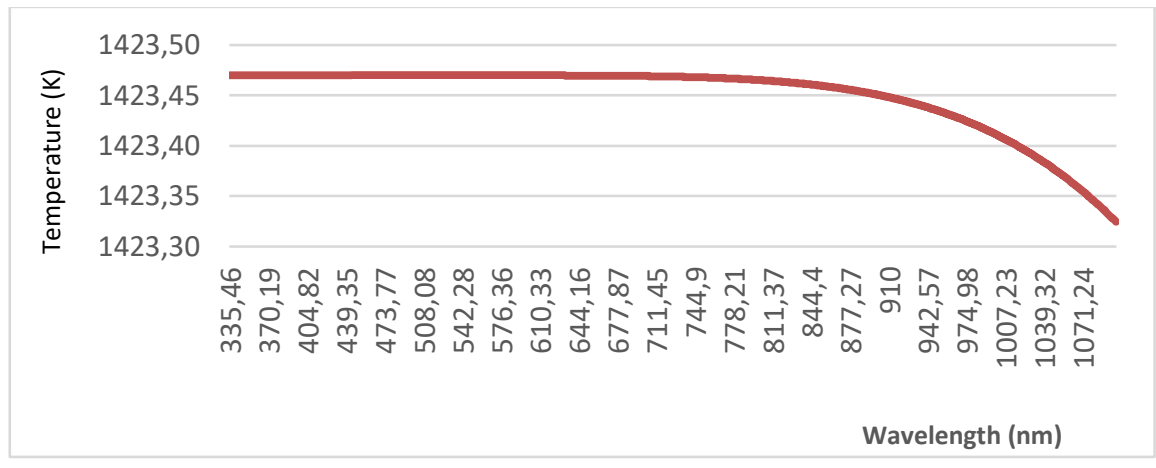

Figure 4 Temperature estimation by sequential method

The Levenberg-Marquardt Inverse Method was used to calculate simultaneously the spectral emissivity variation and the flame temperature. In the inverse method were used the procedure of parameters estimation and polynomial and sinusoidal models for emissivity variation. In figure 5 is shown the comparison of the numerical convergency for three models used in the inverse method. Polynomial model converged about after 320 iterations and sinusoidal model converge faster.
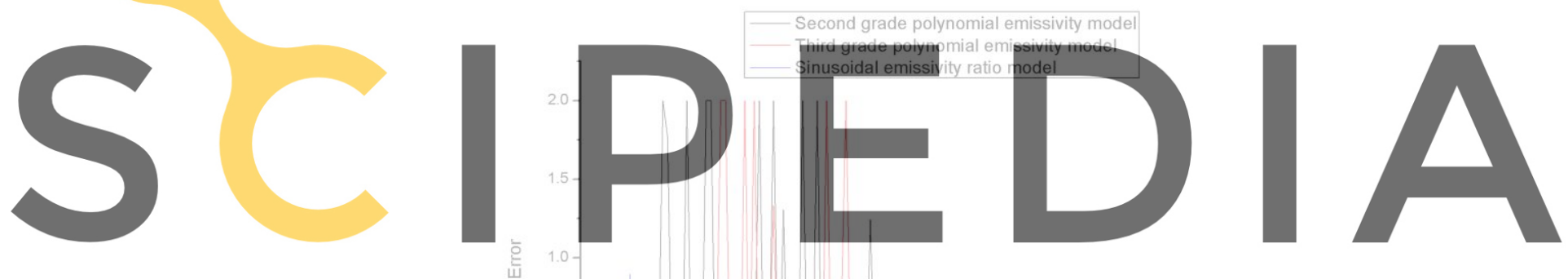

Register for free at https//www.scipedia.com to download the version without the watermark

Figure 5. Convergence comparison of second and third order polynomial emissivity estimation and sinusoidal emissivity ratio estimation from for experiment 6.

In figure 6 is shown the comparison of the flame emissivity estimation by the two color method and by the Levenberg-Marquardt inverse method for three set of experimental data. It can be seen good agreement in the range of emissivity values and in the variation profile of the spectral emissivity.

Flame temperature estimation by the three methods is shown in Table 3. Estimations of the flame temperature by the two color method is made by selecting a proper spectral range where spectral emissivity is approximately constant. Temperature calculation by sequential method gives a close temperature estimation along all spectral range and is close to standard two color 
method values. Simultaneous estimation of flame temperature and emissivity by the Levenberg-Marquardt method is in agreement with estimations by the two color method. For the spectral data in this work the third order polynomial model give estimations closer with two color method estimations. Sinusoidal model in this case gives bad estimations.
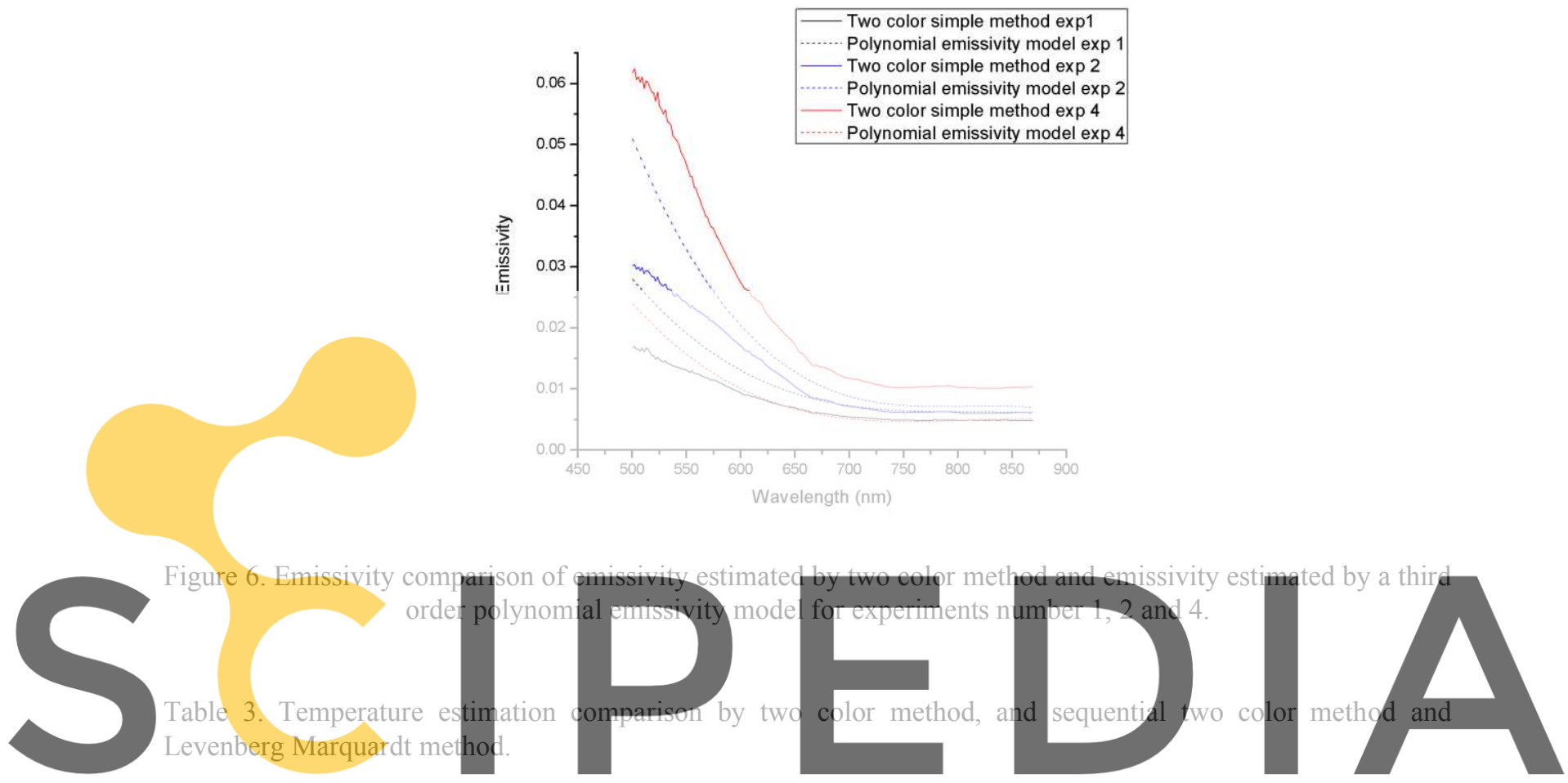

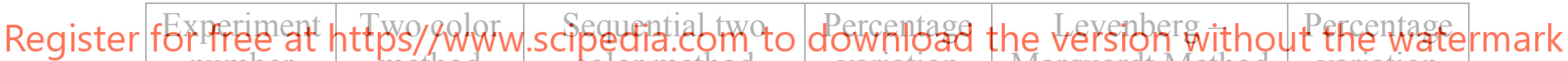
number

\begin{tabular}{|l|l|l|l|l|l|}
\hline 1 & 1562.50 & 1562.49661 & $0.021696 \%$ & 1529.2 & $2.131 \%$ \\
\hline 2 & 1544.00 & 1543.99665 & $0.021697 \%$ & 1522.2 & $1.412 \%$ \\
\hline 3 & 1507.47 & 1507.46673 & $0.021692 \%$ & 1420.6 & $5.765 \%$ \\
\hline 4 & 1581.30 & 1581.29657 & $0.021691 \%$ & 1692.1 & $7.007 \%$ \\
\hline 5 & 1558.79 & 1558.78662 & $0.021683 \%$ & 1420.8 & $8.853 \%$ \\
\hline 6 & 1430.50 & 1430.4969 & $0.021671 \%$ & 1430.4 & $0.007 \%$ \\
\hline
\end{tabular}

To comparison, a portable imaging system was used to measure the flame temperature during a combustion test. The imaging system measure the average flame temperature in the focused zone, while the spectrometric method can measure the flame temperature in a local point. In Figure 8 is show the flame temperature measured in experiment 1 using the thermal imaging method. This result agrees with estimations of flame temperature calculated based in spectral data collected by the spectrometric system. 


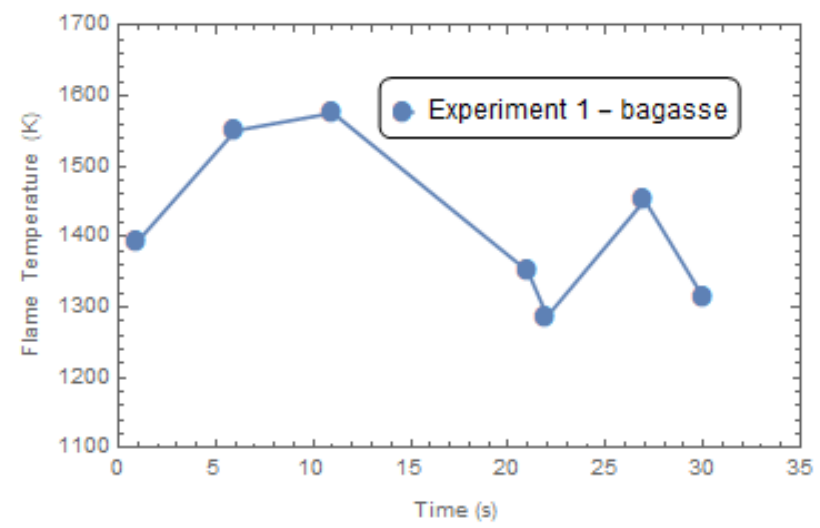

Figure 8. Temperature measurement by thermal portable system, during combustion in experiment 1.

\section{CONCLUSIONS}

A sequential two-color method including the emissivity spectral variation was applied and compared with results from standard two-color method. Estimations of temperature in both methods agree.

The Levenberg-Marquardt Inverse Method to simultaneous estimation of flame spectral emissivity variat model did not give a gor

Flame temperature est

Values of flame

Marquardt Inverse Methods are in reasonable
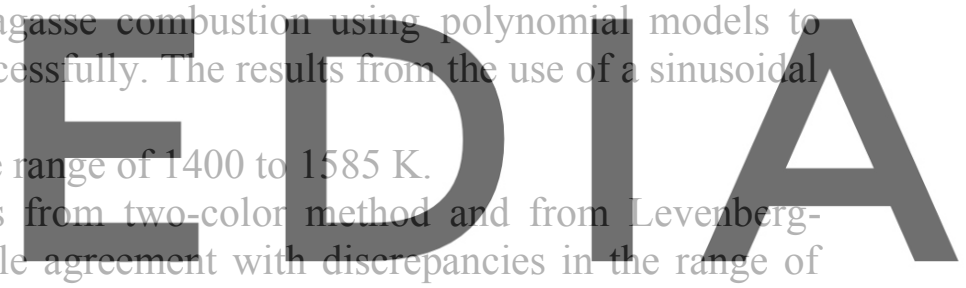

$0.007 \%$ to $8.85 \%$.

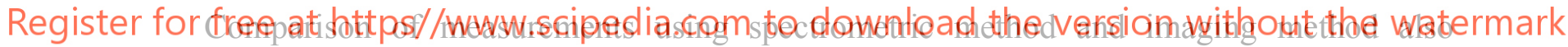
agrees.

\section{ACKNOWLEDGMENTS}

The authors acknowledge the financial support of the Project Concytec (Perú) - World Bank "Improvement and Expansion of Services of the National System of Science, Technology and Technological Innovation" 8682-PE, through its executing unit Fondecyt. (contract 010-2019-FONDECYT). The first author also thanks FAPESP of Brazil (Process 2016/01493-9). The third author thanks the "Companhia de Saneamento Básico do Estado de São Paulo" (Sabesp) for scholarships support.

\section{REFERENCES}

[1] Rossow R.A., Blackbody temperature calculation of visible and near infrared spectra for 
gas furnaces. PHD Thesis. Columbia University. USA. 2005.

[2] Sun Y.P., Lou C., Zhou H.C., A simple judgment method of gas property of flames based on spectral analysis and the two color method for measurements of temperatures and emissivity, Proc. Combust. Inst. (2011) 33: 735-741.

[3] Liu H., Zheng S., Zhou H.C. and Qi C., Measurement of distributions of temperature and wavelength-dependent emissivity of a laminar diffusion flame using hyper-spectral imaging technique. Measurement Science and Technology (2015) 27(2):1-10.

[4] Zheng S., Ni L., Liu H., Zhou H.C., Measurement of the distribution of temperature and emissivity of a candle flame using hyperspectral imaging technique. Optik (2019)183: 222-231.

[5] Shao L.C., Zhou Z., Chen L.P., Guo L.Z, Chen B., Liang L.J. Study of an improved twocolour method integrated with the emissivity ratio model and its application to air- and oxy-fuel flames in industrial furnaces. Measurement (2018) 123: 54-61

[6] Ozisik N. and Orlande H.R.B. Inverse heat transfer: fundamentals and applications. Taylor \& Francis, (2010).

[7] Adolfo Lutz Institute, Physical-Chemical Methods for Food Analysis, 4 ed., Series: Analytical Standards of the Adolfo Lutz Institute (2016). (in Portuguese).

[8] Modest M.F. Radiative heat transfer, 3 ed., Elsevier, (2013)

[9] Fu T., Tan P., Pang C., Zhao H., and Shen Y. Fast fiber-optic multi-wavelength pyrometer. Review of Scientific Instruments, (2011) 82: 064902. doi: 10.1063/1.3596567.

[10] Jan W.J., Lou C., Cheng Q., Zhao P., Zhang X.Y. In situ measurement of alkali metals in a MSW incinerator using spontaneous emission spectrum, Appl. Sciences (2017) 7(3): 263. https://doi.org/10.3390/app7030263. 